\title{
Distressing Near-Death Experience: An Iranian Shia Muslim Case
}

\author{
Alinaghi Ghasemiannejad Jahromi, PhD \\ Department of Near-Death Studies, Isfahan, Iran \\ Ali Imaninasab, MA \\ University of Quran and Hadith
}

\begin{abstract}
In this article we present a distressing near-dear experience (NDE) that a 23-year-old Iranian Shi'ite Muslim man described having experienced five years previous, during coma following a serious car accident. Given that very few Muslims, especially Iranians, have reported NDEs, one of our aims in presenting this case was to begin to fill this void in the near-death studies literature. We provide extensive quotations from our 40-minute interview with this experiencer, in which he described the NDE itself as well as aftereffects of it, including experiences of disclosing it to others. We conclude with a discussion about the relationship between his NDE and Islamic beliefs as well as what his case can offer regarding an understanding of the role of culture in NDEs.
\end{abstract}

KEY WORDS: religion, Qur'an, case study, distressing near-death experience, Iran

After surviving a close brush with death due to actual or anticipated illness or injury, approximately $10 \%$ of people report that during the close brush they had a typically real and lucid experience of their con-

\footnotetext{
Alinaghi Ghasemiannejad Jahromi, $\mathrm{PhD}$, is a couple therapist at Tooba Mental Health Institution in Isfahan, Iran. In pursuit of his primary area of scholarly inquiry - the nature, content, and aftereffects of near-death experiences (NDEs) - he founded and now leads the Department of Near-Death Studies in Isfahan to promote research and to educate Iranians about NDEs. Ali Imaninasab, MA, is a master's student of theology at the University of Quran and Hadith in Qom, Iran. His primary area of scholarly inquiry is research into NDEs and the post-mortem destiny of nonMuslims from the viewpoint of Islamic sources. The authors wish to thank Mr. Alireza for the valuable information that he provided about his NDE. We also thank Elham Shabani and Habib N. Nobakht for their help, and Janice Miner Holden, editor of this Journal, for her extensive editorial assistance, in the preparation of this article. Correspondence regarding this article should be sent to Dr. Ghasemian at email: ali .ghasemian@ymail.com.
} 
sciousness functioning apart from their physical body, observing the material world and observing and interacting with unearthly environments and entities: a near-death experience (NDE; Zingrone \& Alvarado, 2009). The scholarly literature on NDEs has been dominated by accounts from English-speaking Western experiencers who had pleasurable experiences-those pervaded by feelings such as peace, joy, and love (Noyes, Fenwick, Holden, \& Christian, 2009; Zingrone \& Alvarado, 2009). Although NDEs have been reported in non-Western countries, such reports are rare (Kellehear, 2009), and particularly rare are accounts from Muslim countries (Fracasso, Aleyasin, Friedman, \& Young, 2010; Ghasemiannejad, Long, Noori, \& Farahnakian, 2014; Kreps, 2009; Long, 2010; Nahm \& Nicolay, 2010). Similarly, although some experiencers (NDErs) have reported distressing experiences - those pervaded by feelings such as terror, horror, or guilt-such reports are relatively much less frequent (Bush, 2009; Greyson \& Bush, 1992). Particularly rare are experiences that fit both categories-distressing non-Western NDEs-and virtually non-existent in the literature are accounts of distressing NDEs from Muslim countries. Thus, cases of this type promise to make a unique contribution to a comprehensive understanding of NDEs and possibly the role of culture in that understanding.

Belief in the potential for a hellish afterlife is inherent in Islam. In the sacred book of Muslims, the Holy Qur'an, the existence of hell in the afterlife has been mentioned repeatedly. The features of hell, as well as life in it, have been described with phrases such as: trees whose fruits are bitter and unpleasant $(37,66)$, the existence of seven gates in hell each specific to a certain group of the damned $(15,44)$, burning flames of fire $(70,15)$, the existence of a well or a valley specific to the disbelievers $(51,60)$, chains around people's necks $(40,71)$, hot and burning springs $(88,5)$, boiling water $(37,67)$, and unsavory foods and painful torments $(73,13)$.

In this article, we present the case of an Iranian man's distressing NDE and some of its aftereffects as well as his experiences disclosing it to others. We then discuss implications of this case for an understanding of the relationship between NDEs and religion as well as culture.

\section{The Case}

The subject of this case study contacted us after he saw a flyer we had created about NDEs. After he expressed his willingness to share his 
account with us, as he was not able to come to our location in Isfahan or make a video call, we invited him to a phone call in order to conduct a semi-structured, in-depth interview in Farsi that ended up lasting 40 minutes. The following narrative represents our English translation of his account.

At the time of our interview, Mr. Alireza-who agreed to disclose his real name-was an unmarried 23-year-old man from a small town near Mashhad, the second most populous city in Iran and the capital of Razavi Khorasan Province. He reportedly was on the verge of death in 2012 due to injuries from a motor cycle accident. Doctors had lacked hope for his survival, but one of Alireza's companions insisted on his surgery. He described the accident:

In mid-May of 2012, I was riding a motorcycle on a street, named Lashgar, in which a car was double-parked. I suddenly hit the car and my head hit its rear windshield. It was such a terrible accident; doctors said I was lucky to survive, and I know that this was the will of God.

After the accident, I was sent to the hospital. Because my injuries were severe and I had no vital signs, medical personnel pronounced me dead and placed a white sheet over my entire body. I realized that they pulled this sheet over me, but I could not move. I could not even move my fingers. A man was there and asked where they were taking me. The nurses told him that I was dead. The man insisted that he should see for himself. Then I felt a finger coming toward my nose. He must have felt the breath coming out of my nose, because then he said that I was still alive. The nurses replied, "This man is dead; even if he breathes, he will not survive." The man repeated insistently that, "No, he should survive."

Finally, they took me to the operating room and quickly sutured my wounds, and then they sent me to the main hospital of the city. I heard people talking about how expensive it would be for my family to pay for my treatment, but I could not react due to my injuries. The bottom of my chest was split open from glass that had punctured my abdomen, and it was horribly open. There was a disagreement between the doctors regarding whether to continue my treatment. Eventually, they brought me and my companions-some of my relatives and friends- to Taleghani Hospital in Mashhad, where they told us they did not have the proper equipment to treat me. They then took me to Emdad Hospital. When I arrived there, I went into a coma, and I remained in that condition for three months.

Alireza continued by describing what he became aware of next:

Then the only thing I realized was that everything became dark. A curtain appeared behind me, which I passed through. The space be- 
hind the curtain was very unpleasant and horrible. Until that moment, I had never seen such things with my own eyes. Behind the curtain was a space where the hands and feet of the people were bound with shackles and manacles. Anyone who entered this place would be pushed forward. I also wanted to put myself into these shackles and manacles to go along with others. But there were people there who told me, "You should wait for your letter to come and we see what happens. Wait here for now!"

In this horrifying place, there were several groups of individuals. One group was in fire where they were being burned by the heat. Another group was also in the fire, but they were shaking of cold. The last group was somewhat in between, meaning there was neither coldness nor warmth: They were very normal. For this last group, which seemed to be in a balanced position, there was a giant-like creature with a fire stick in his hand. When people would go forward, he would wound them, getting them to move by prodding them in the waist with this fire stick. I have never understood why these people were being tormented. No one there would talk to me, and I just stood there silent, watching.

As Alireza continued, he emphasized the element of fire:

As I looked around, I saw a city that had been completely burned. It was very scary, and I had seen these scenes only in the movies. Actually, I had not seen anything exactly like this until then. It was very weird. Although we are Muslims and have often read or heard of such things, hearing doesn't have nearly the impact of actually seeing it. It was a very strange place. I was really scared.

Alireza continued by describing his way back to the body:

Some time passed, and a letter came. Next, the person who stood at the door and received the letters put shackles and manacles on some people but told others to go back. I lingered there a long time, and I had been standing there for so long that I was apparently among the ones who would be returning.

My letter came from a man whose face was very luminous. I was still unclear why I was being sent back. What was written on that letter that they returned me to physical life? That luminous-faced man did not even introduce himself to me, nor could I tell whether he was a special person. I just felt that he might be one of the Imams. This was my own interpretation, and I'm still not sure who that person was. He then sent the letter to someone else and said that this was the letter of someone. Then he said that I should return to my physical body.

I was very insistent about staying there. I really wanted to stay and be shackled. True, I was scared, but I really wanted to go with them to see how the other side was. I saw that they were burning or beating these people. But when I saw that everyone was going to the 
same side, I also wanted to go that way, without taking into account what would follow and what would happen to me. Maybe, it was not the feeling of love, but it was a sense of fear to come back. I was afraid that they would bring me back. I was afraid of the darkness that was everywhere with not even a hint of brightness. There were also other people who, like me, had been standing there for several hours. The process was taking too long. I wanted neither to stay in line nor to return. I asked to go with those being shackled and manacled. The people in charge came then and denied my request, exclaiming that I should return. The same luminous face reappeared, took my hand, and brought me back to physical life.

Eventually, Alireza was restored to earthly life:

When I became conscious, I was in the intensive care unit. My mother told me that I had been in coma for three months. I was on the hospital bed, and when I opened my eyes, I realized that they had put cotton on them. At first I thought I was in that dark space, because my eyes did not see anything. But when my hands and toes moved, I realized that I was alive.

When Alireza described his experience to others, their negative and unsympathetic reactions made him decide not to talk about it with anyone:

The worst thing was that when I was talking to others, they would ridicule me and my words and would tell me, "Who has ever seen and heard such things?" These reactions bothered me a lot. So I preferred not to tell anyone anything and chose to keep the experience to myself.

Alireza described three aftereffects of his experience: cautiousness in social relations, reduced aggression, and increased interest in religious activities. Regarding social relations:

Now, and after my experience, I do not like to interact with anyone. I became very uncommunicative; however, I value and respect my mother very much. I do not become very comfortable and intimate with others like before, maybe only saying hello and greeting. I feel that I am afraid of myself, so I do not make friends anymore. That is, I am afraid that I would say something that others would misunderstand or find annoying. Presently, I have intimate relationships only with close members of my family. My mother and I are very close, and I am grateful to her.

\section{Regarding anger:}

Before, I would get angry frequently, and this made me unsociable, but now things are getting better. No one could speak to me more than 10 words before I would lose my temper. But now I am very calm, and 
I get angry less frequently. I can say that I am very imperturbable now. Really, my anger has subsided now.

Regarding religious activities:

Now, I am a permanent member of the congregation and mosque. Before the experience, I would pray very rarely, but now, I do all my prayers on time.

Before my experience, I wasted my time by wandering around. I did not understand whether there was a God. I would not set time for religious activities. Now, when I encounter some people, I tell them to say their prayers, but they often tell me that this is none of my business. And I do not like this kind of conflict to happen. So, I like these prayers and religious activities to start from little children. I talk to the parents of the children and tell them to appreciate the children who come to congregation and the mosque and help them say their prayers, especially the morning prayers.

\section{Discussion}

In the following discussion, we will first address the circumstances of this NDE, then its content, and then its aftereffects, including disclosure of the experience and changes in the experiencer. We will consider these aspects in relation to the existing literature on NDEs in general and distressing NDEs in particular, including the possible roles of culture and, specifically, religion in NDEs.

Despite the fact that many NDErs report feeling joy, happiness, and relief from pain in their NDEs, others consider their experiences hellish, frightening, scary, and unpleasant (Atwater, 1992; Serdahely, 1995). Based on a review of the literature, Bush (2012) asserted that one out of five reported NDEs may be negative or distressing. Alireza's experience was among the distressing type. Researchers have found that NDEs are "equal opportunity" experiences, occurring without discernable difference to people of all demographics and in all types of circumstances, including illness and both accidental and self-inflicted injuries, as well as in all states of consciousness, ranging from alert consciousness to coma to cardiac arrest (Zingrone \& Alvarado, 2009). Thus researchers have been unable to identify factors that enable them to predict who, among survivors of a close brush with death, will or will not have an NDE and, of those who do, who will have a pleasurable or distressing one (Holden, Long, \& MacLurg, 2009). In this way, nothing about Alireza's demographics or the physical circumstances in which his NDE occurred are remarkable or would necessarily pre- 
dict either that he would have an NDE or that the NDE he had would be of the distressing type.

Regarding the content of NDEs, a useful metaphor is the human face (Holden, 2017). Just as some facial features are universal to virtually all humans-eyes, nose, and mouth in a particular configurationsome NDE features appear universal, including unearthly places and beings (Kellehear, 2009). Just as some facial features correspond to a subgroup such as a person's particular race-for example, eye shapesome features of NDEs appear to correspond to cultural subgroupssuch as the appearance of particular religious figures known in the NDEr's culture. And just as some facial features are individual, making every face ultimately unique, so might the form a particular NDE feature takes be unique to a particular NDEr. Regarding the content of Alireza's NDE, some elements corresponded to those in the predominantly Western NDE literature on distressing experiences, including darkness, loneliness, fear (Grey, 1985), confusion (Gallup, 1982), observing horrible and devilish creatures (Lindley, Bryan, \& Conley, 1981), and an entrance to horrible spaces (Atwater, 1992); these elements have appeared repeatedly, if not universally, in distressing NDEs. On the other hand, some elements correspond to the features of hell as described in the Qur'an and the traditions of the Prophet Muhammad and Shi'a Imams, including chains and a letter-a likely reference to the record of deeds of all one's lifetime actions that serves as a basis to judge one's afterlife fate; these elements seem to be associated with Alizera's culture and religion. And still other elements seem unique to Alireza's NDE, including the three burning groups of people and the fire stick; these particular features have not, to our knowledge, been reported by any other NDEr, nor are they images from the Qur'an or Iranian culture. Although, like Alireza, pleasurable NDErs have often reported wanting to stay and even arguing to stay in the unearthly realm, they wanted to stay in order to remain in bliss, whereas Alireza reportedly wanted to stay to join others who were suffering, with whom he apparently felt a sort of kinship, in order to learn what lay beyond what he could currently see, and out of a fear that returning to physical life might involve immersion in darkness - with his desire to know and his fear reportedly rendered him impervious to the suffering he would experience in the process. To our knowledge, this motivation to endure suffering out of a sense of kinship and curiosity and a fear that returning to physical life would involve immersion in darkness have not been reported in the distress- 
ing NDE literature. It illustrates another possibly unique feature of Alireza's experience.

Thus, regarding the question of whether NDE content is influenced by culture, and specifically in this case religion, or whether culture and religion might instead be filters through which an NDEr makes sense of an essentially otherworldly experience, Alireza's account could be interpreted to provide some support for each perspectives in part and for neither perspective exclusively. We will return to this point in our conclusion.

Alireza reported that his attempts to disclose his NDE to others were met with substantial disbelief and discounting - to which he responded by discontinuing disclosure except with a very few people whom he discerned to be open and accepting. Other NDErs have described this type of disclosure experience and reaction (Holden, Kinsey, \& Moore, 2014). Although Holden et al. found that more disclosure harm was reported by those who had relatively deeper NDEs and who disclosed relatively sooner following their NDEs, they did not ask whether NDErs experienced more disclosure harm if they had distressing rather than pleasurable NDEs. This latter factor makes intuitive sense and represents a possible topic for future research inquiry.

Alireza attributed to his NDE three subsequent changes in himself. One change was reduced anger and aggression toward and increased patience with others. This change corresponds to what NDErs have reported in the existing literature (Noyes et al., 2009). Following their NDEs, experiencers report feeling more empathy for, concern for, tolerance of, and patience with others. From the extent of his narrative, it is not possible to determine exactly how his NDE resulted in this change. Future qualitative researchers would do well to ask follow-up questions that clarify such critical nuances for an understanding of the psychospiritual dynamics in the aftermath of an NDE.

Another change was increased interest in religious activities. Here again is an aftereffect frequently reported in the NDE literature (Noyes et al., 2009). Although NDErs more often describe becoming more spiritual but less religious-finding religion too confining in belief and practice to accommodate what the NDEr now knows of the spiritual domain - a substantial minority of NDErs become more immersed in their pre-NDE religion-the pattern Alireza demonstrated. Typical of other NDErs who previously disbelieved or gave little to no thought to God, Alireza apparently came not merely to believe but actually to know that God exists.

Alireza's disclosure experiences and his new commitment to reli- 
gion apparently led to his third change: cautiousness in social relations. After harmful disclosure experiences, he decided largely to discontinue disclosure. In addition, in his zeal to proselytize regarding his new commitment to religion, he perceived that others considered him to have been pushy and invasive. Thus he inhibited himself in self-expression, for fear of the possibility of creating conflict with others or annoying them. At the same time, he expressed gratitude for finding in his mother a rare confidante, and he described learning to channel his religious zeal into aligning with parents in encouraging the religious upbringing of their children. The fact that, upon seeing our flyer, he initiated contact with us and followed through with a phone interview indicates that his desire to discuss his NDE persisted despite negative disclosure experiences; he acted on that desire upon discovering in us a potentially receptive audience. These experiences, both painful and adaptive, characterize the typical integration process for NDErs (Stout, Jacquin, \& Atwater, 2006). Though Alireza did not mention ever having considered seeking services from mental health providers such as psychologists and counselors, he might have found-and still could find-unique value in his ongoing process of integration, which research suggest can take an average of 7 years (Clark, 1994; Foster, James, \& Holden, 2009; Stout et al., 2006).

Alireza's distressing NDE represents a case that seems to correspond in circumstances; content-with universal, culturally-specific, and unique individual features; and aftereffects to distressing NDEs already described in the professional literature. A clearer understanding of the specific influence of religion on the content and/or interpretation of distressing non-Western NDEs depends upon the accumulation of a much larger number of cases. Alireza's account indicates that such cases may very well exist if researchers can succeed in finding them.

\section{References}

Atwater, P. M. H. (1992). Is there a hell? Surprising observations about the neardeath experience. Journal of Near-Death Studies, 10, 149-60. doi:10.17514/ JNDS-1992-10-3-p149-160.

Bush, N. (2009). Distressing Western near-death experiences: Finding a way through the abyss. In J. M. Holden, B. Greyson, \& D. James (Eds.), Handbook of near-death experiences: Thirty years of investigation (pp. 63-86). Santa Barbara, CA: Praeger/ABC-CLIO.

Bush, N. (2012). Dancing past the dark: Distressing near-death experiences. Cleveland, TN: Parson's Porch Books. 
Clark, K. (1984). Clinical intervention with near-death experiencers. In B. Greyson \& C. P. Flynn (Eds), The near-death experience: Problem, prospects, perspective (pp. 242-255). Springfield, IL: Charles C. Thomas.

Foster, R., James, D., \& Holden, J. (2009). Practical applications of research on near-death experiences. In J. M. Holden, B. Greyson, \& D. James (Eds.), Handbook of near-death experiences: Thirty years of investigation (pp. 235258). Santa Barbara, CA: Praeger/ABC-CLIO.

Fracasso, C. L., Aleyasin, S. A., Friedman, H., \& Young, S. M. (2010). Neardeath experiences among a sample of Iranian Muslims. Journal of Near-Death Studies, 29, 265-272. doi:10.17514/JNDS-2010-29-1-p265-272.

Gallup, G., Jr., with Proctor, W. (1982). Adventures in immortality: A book beyond the threshold of death. New York, NY: McGraw-Hill.

Ghasemiannejad, A., Long, J., Noori, F. \& Farahnakian, K. (2014). Iranian Shiite Muslim near-death experiences: Features and aftereffects including dispositional gratitude. Journal of Near-Death Studies, 33, 30-42. doi:10.17514/ JNDS-2014-33-1-p30-42.

Foster, R. D., James, D., \& Holden, J. M. (2009). Practical applications of research on near-death experiences. In J. M. Holden, B. Greyson, \& D. James (Eds.), Handbook of near-death experiences: Thirty years of investigation (pp. 235-258). Santa Barbara, CA: Praeger/ABC-CLIO.

Grey, M. (1985). Return from death. London, England, UK: Arkana.

Greyson, B., \& Bush, N. E. (1992). Distressing near-death experiences. Psychiatry, 55, 95-110.

Holden, J. M. (2017). Near-death experiences. In R. D. Foster \& J. M. Holden (Eds.), Connecting soul, spirit, mind, and body: A collection of spiritual and religious practices in counseling (pp. 89-97). Alexandria, VA: Association for Spiritual Ethical, and Religious Values in Counseling. Retrieved from https:// www.library.unt.edu/aquiline-books/connecting-008-3.

Holden, J. M., Kinsey, L., \& Moore, T. R. (2014). Disclosing near-death experiences to professional healthcare providers and non-professionals. Spirituality in Clinical Practice, 1(4), 278-287. doi:10.1037/scp0000039.

Holden, J. M., Long, J., \& MacLurg, B. J. (2009). Characteristics of Western neardeath experiencers. In J. M. Holden, B. Greyson, \& D. James (Eds.), Handbook of near-death experiences: Thirty years of investigation (pp. 109-134). Santa Barbara, CA: Praeger/ABC-CLIO.

Kellehear, A. (2009). Census of non-Western near-death experiences to 2005: Observations and critical reflections. In J. M. Holden, B. Greyson, \& D. James (Eds.), Handbook of near-death experiences: Thirty years of investigation (pp. 135-158). Santa Barbara, CA: Praeger/ABC-CLIO.

Kreps, J. I. (2009). The search for Muslim near-death experiences. Journal of Near-Death Studies 28, 67-86. doi:10.17514/JNDS-2009-28-2-p67-86.

Lindley, J. H., Bryan, S., \& Conley, B. (1981). Near-death experiences in a Pacific Northwest American population: The Evergreen study. Anabiosis: The Journal for Near-Death Studies, 1, 104-124. doi:10.17514/JNDS-1981-1-2-p104-124.

Long, J., with Perry, P. (2010) Evidence of the afterlife: The science of near-death experiences. New York, NY: HarperCollins.

Nahm, M., \& Nicolay, J. (2010). Essential features of eight published muslim near-death experiences: An addendum to Joel Ibrahim Kreps's "The Search for 
Muslim Near-Death Experiences." Journal of Near-Death Studies, 29, 255263. doi:10.17514/JNDS-2010-29-1-p255-263.

Noyes, R., Jr., Fenwick, P., Holden, J. M., \& Christian, S. R. (2009). Aftereffects of pleasurable Western adult near-death experiences. In J. M. Holden, B. Greyson, \& D. James (Eds.), Handbook of near-death experiences: Thirty years of investigation (pp. 41-62). Santa Barbara, CA: Praeger/ABC-CLIO.

Serdahely, W. (1995). Variations from the prototypic near-death experience: The "individually tailored" hypothesis. Journal of Near-Death Studies, 13, 185196. doi:10.17514/JNDS-1995-13-2-p185-196.

Stout, Y. M., Jacquin, L. A., \& Atwater, P. M. H. (2006). Six major challenges faced by near-death experiencers. Journal of Near-Death Studies, 25, 49-62. doi:10.17514/JNDS-2006-25-1-p49-62.

Zingrone, N. L., \& Alvarado, C. S. (2009). Pleasurable Western adult near-death experiences: Features, circumstances, and incidence. In J. M. Holden, B. Greyson, \& D. James (Eds.), Handbook of near-death experiences: Thirty years of investigation (pp. 17-40). Santa Barbara, CA: Praeger/ABC-CLIO. 